\title{
Epidemiology of non-invasive Aspergillosis of the maxillary sinuses - Clinical data from the Maxillofacial Surgery Clinic of the Medical University in Lublin, Poland, 2005-2014
}

\author{
Anna Gawęda', Jolanta Wojciechowicz' , Grzegorz Barszczewski', Tomasz Tomaszewski ${ }^{1}$ \\ ${ }^{1}$ Chair and Clinic of Maxillofacial Surgery, Medical University of Lublin, Poland \\ Gawęda A, Wojciechowicz J, Barszczewski G, Tomaszewski T. Epidemiology of non-invasive Aspergillosis of the maxillary sinuses - Clinical \\ data from the Maxillofacial Surgery Clinic of the Medical University in Lublin, Poland, 2005 - 2014. J Pre-Clin Clin Res. 2014; 8(2): 95-99. doi: \\ $10.5604 / 18982395.1135658$
}

\begin{abstract}
Fungi are organisms which occur in the human environment. One of the potential pathogenic fungi is Aspergillus which belongs to mould, and is an etiological factor of non-invasive fungal paranasal sinusitis.

Objective. Epidemiological analysis of aspergillosis of the maxillary sinuses.

Material and methods. Retrospective analysis of the medical histories of 41 patients treated in the Maxillofacial Surgery Department of Medical University in Lublin, Poland between 2005-2014 due to non-invasive aspergillus maxillary sinusitis. The patients' gender, age, and etiopathogenesis of the condition with signs and symptoms, and methods of treatment were analysed. Histological examination was crucial in the final diagnosis.

Results. The majority of the patients constituted women aged 29-72. The most common complaints were suborbital pain, rhinorrhoea and impaired nasal ventilation. All the patients were treated surgically, and pharmacologically with Fluconazole. Conclusion. Fungal maxillary sinusitis should be taken into account in every case of chronic maxillary sinusitis resistant to standard treatment. Women are more susceptible to Aspergillosis, and the risk factors for the disease are endodontic treatment of the maxillary teeth and fistula antro-oralis post extractionem. Surgical treatment sometimes should be complemented by pharmacological antimycotic treatment.
\end{abstract}

\section{Key words}

Aspergillosis, chronic sinusitis, therapy, pathology

\section{INTRODUCTION}

Fungi occur commonly in nature and play a crucial role of reducents which enable proper matter circulation. Some fungal species may be pathogenic for humans. Fungoid infections are less frequent than bacterial or viral ones. Most often they are opportunistic and affect mainly people with lowered immunity [1]. The course of the disease is severe in patients suffering from AIDS and those treated with immunosuppressives [2]. Fungoid infections are the most menacing among this group of patients since they may be invasive and fulminant. The growing number of people with immunity deficiency results in an increase in the number of fungoid infections which become a serious therapeutic problem for specialists.

One of the potential pathogenic fungus is Aspergillus, rated as mould fungus which include 130 species. The most significant fungus in medicine is Aspergillus fumigatus, which causes atopic diseases less frequently, however, compared to other mould fungi since it occurs in nature in scarce amounts [2], although it is the most frequent etiological cause of fungal nose infection and nasal sinusitis $[3,4]$. A. fumigatus and A. flavus are the most often isolated strains [5]. From $3-10 \%$ of patients suffering from sinusitis

Address for correspondence: Jolanta Wojciechowicz, Chair and Clinic of Maxillofacial Surgery, Medical University of Lublin, Staszica 11, 20-081 Lublin, Poland E-mail: lanyfztk@wp.pl

Received: 19 October 2014; accepted: 12 November 2014 are diagnosed with fungal infection [2]. The infections may be contracted via:

1) air route - aspirating a large amount of fungal spores (refers to the regions of high concentration of spores in the air) $[1,5,6]$;

2) tooth-related route - secondary to dental interventions (forcing tooth root into the sinus, forcing endodontic material used in canal filling into the cavity of the sinus, fistula antro-oralis);

3) or the mixed type - fungus aspirated from the air may remain in the cavity of the sinus for many years without infecting it, but in some favourable conditions (sinus ventilation disorder, a foreign body) the fungal colony grows and causes sinusitis [1].

According to Henick and Kennedy there are 4 clinical types of fungal paranasal sinusitis [14]:

1) Non-invasive sinusitis;

2) Invasive sinusitis;

3) Allergic sinusitis;

4) Fulminant sinusitis.

Non-invasive sinusitis is characterised by the lack of mucosa and some more deeply located structures, and is the most common in immunocompetent patients, affecting more women than men $[4,5,6,7]$. Chronic unilateral sinusitis (most often maxillary) lasting several months or years is the clinical picture of the disease. Differential diagnosis should cover chronic bacterial infections, granular inflammations, 
sinus polyposis, mucoceles, pyoceles, primary and metastatic sinus tumours [3].

Patients'medical histories, physical examination, imaging and sinus endoscopy are essential in the diagnosis of fungal paranasal sinusitis. The final diagnosis is made on the basis of the histopathological examination of the material removed from the sinus [8]. Symptoms including suborbital pain and oedema, chronic headache, nasal discharge or bleeding, nasal obstruction, and post-nasal drip are of great importance $[1,3,9]$. Medical history of dental procedures, including endodontic treatment for maxillary teeth extraction, is also vital. Endodontic material pushed through to the cavity of the maxillary sinus and fistula antro-oralis favour the development of aspergilloma $[10,11,12]$. Neither intraoral nor extraoral examination show devations; thus, in every case of paranasal sinusitis suspicion, additional imaging (OPG, paranasal sinuses x-ray, CT) should be used as complementary diagnosis, regardless of the etiopathogenesis.

$\mathrm{X}$-rays reveal typical features of chronic sinusitis partial or complete darkening of the cavity of the sinus [1, $5,6,10]$. Pathognomonic picture of the fungal sinusitis is homogeneous darkening of the cavity of the sinus, with a semilunar air space between aspergilloma and the upper wall of the sinus [3]. Computed tomography, due to its higher sensitivity, often shows foreign bodies (such as endodontic material pushed into the cavity of the sinus, or tricalcium phosphorate) in the cavity of the sinus which gather in the aspergilloma.

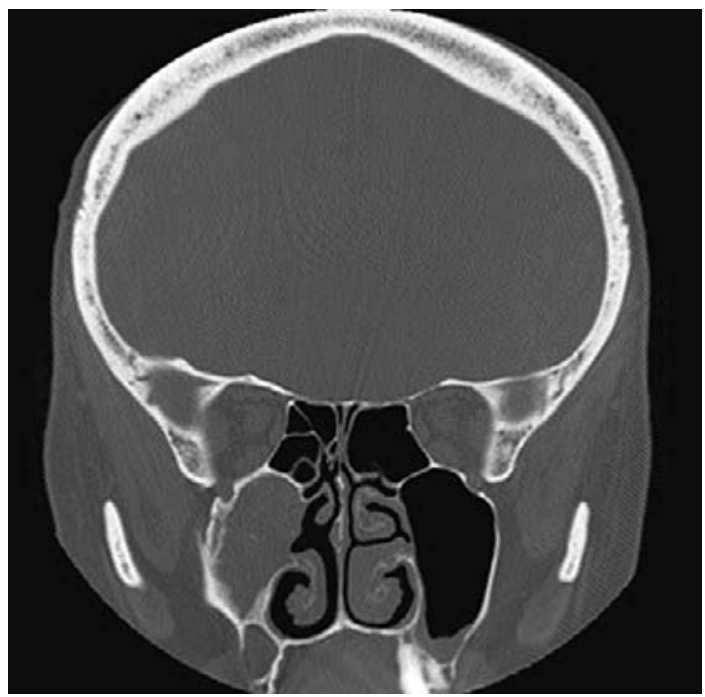

Figure 1. Computed tomography of maxillary sinuses of a 59-year-old female complete darkening of the right maxillary sinus with calcium concrements

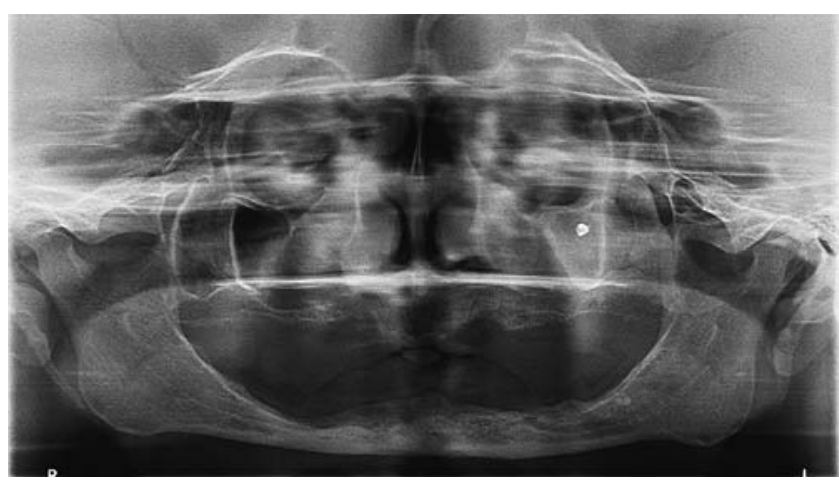

Figure 2. Panoramic radiograph with visible endodontic material in the cavity of the left maxillary sinus

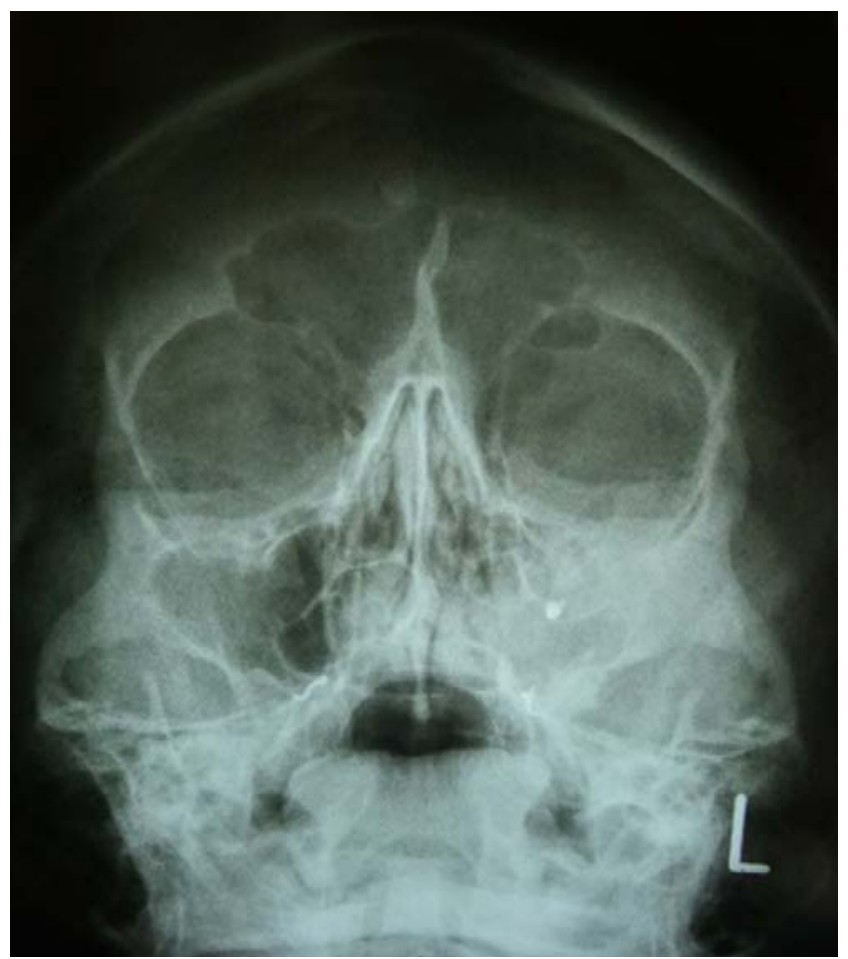

Figure 3. X-ray of the sinuses in 58-year-old female - visible shadow of a foreign body in the cavity of the left maxillary sinus with obstructed aeration.

A foreign body provokes an inflammatory reaction and impairs mucociliary flow which results in sinuses ventilation disturbances, which provide favourable conditions for fungal growth [13].

Table 1 presents criteria for diagnosing Aspergillus sinusitis according to deShazo et al. [5].

Table 1. Criteria for Aspergillus sinusitis diagnosis according to deShazo et al.

1. Darkening of sinus cavity with or without calcification perceptible in imaging

2. Thick mucopurulent discharge in cavity of the sinus

3. Thick and dense mycelium conglomerate in cavity of the sinus not bound with its mucosa

4. Chronic inflammatory reaction of sinus mucosa of different intensity

5. Lack of mucosa, blood vessels or bone infiltration

Treatment of non-invasive Aspergillus sinusitis involves complete removal of pathologic mass from the maxillary vestibule. The Caldwell-Luc surgery procedure has been the standard treatment for many years. It involves gaining access to the maxillary sinus through the oral vestibule, then the canine fossa, and by removing the damaged mucosa and joining the sinus with the lower nasal passage. Nowadays, due to the development of endoscopic techniques, numerous authors highlight the advantage of endoscopic sinus surgery (ESS) over the traditional Caldwell-Luc method [1, 14, 15]. There are 3 endoscopic ways of gaining access to the maxillary sinus [14]:

1) paranasal;

2) single intraoral access;

3) double access. 


\section{OBJECTIVE}

The aim of the study is epidemiological analysis of the medical data of patients admitted to the Maxillofacial Surgery Clinic at the Medical University in Lublin, Poland, during 2005 2014 due to non-invasive Aspergillus maxillary sinusitis.

\section{MATERIALS AND METHOD}

The research involved retrospective analysis of medical histories of 41 patients treated due to non-invasive aspergillus maxillary. The patients' gender and age as well as etiopathogenesis of the condition with clinical signs and symptoms and methods of treatment were analysed.

The diagnosis was made on the basis of the medical history, clinical examination, imaging, (pantomography, computed tomography) and histopathological examination of the material removed surgically from the cavity of the sinus. The results were analysed statistically using the Chi-quadrant test and Mann-Whitney test.

\section{RESULTS}

41 patients diagnosed with Aspergillus sinusitis were admitted to the Maxillofacial Surgery Clinic of Medical University of Lublin during 2005 - 2014. The majority of the group consisted of 33 women aged $29-72$ (average age 48.3). Eight out of 41 patients were men, aged 23 - 61 (average age 41.25). The overall number of women and men in the research group were compared using the Chi-quadrant test; the number of women was statistically higher $(\mathrm{p}<0.05)$. Basic statistical parameters were estimated for the variable of age (Tab. 2) and a histogram was constructed (Fig. 1).

Table 2. Patients' age ( $\mathrm{N}$ - Number of examined patients)

\begin{tabular}{cccccc}
\hline Median & Mean value & Standard deviation & Minimum & Maximum & $\mathrm{N}$ \\
\hline 47.00 & 46.98 & 11.955 & 23 & 72 & 41 \\
\hline
\end{tabular}

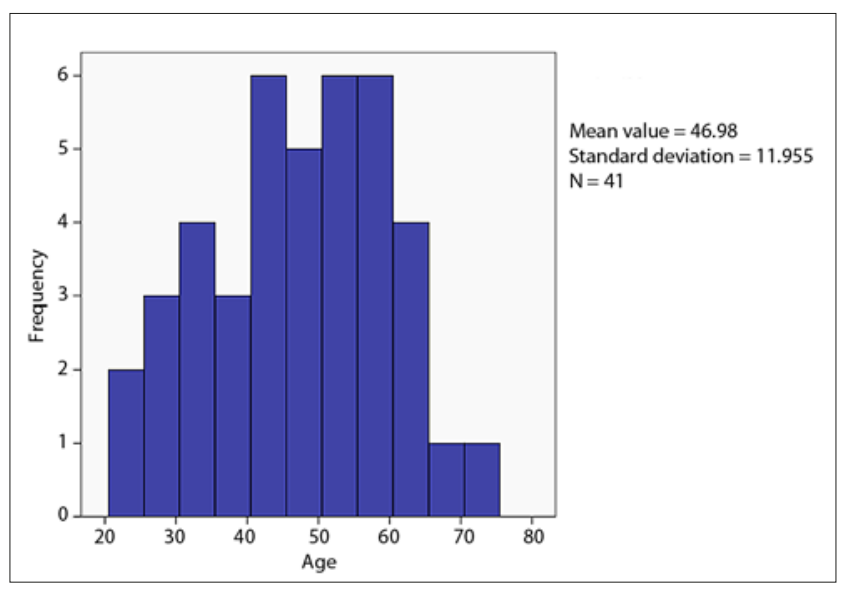

Figure 1. Patients' age - histogram

The most common complaints included suborbital pain (58.5\%), pathological nasal discharge (31.7\%) and impaired nasal patency (22\%) (Tab. 3).
Table 3. Symptoms reported by the patients

\begin{tabular}{lcc}
\hline \multicolumn{1}{c}{ Signs and symptoms } & No. of people $(\mathrm{n}=41)$ & Percentage \\
\hline Suborbital pain & 24 & $58.5 \%$ \\
\hline Rhinorrhoea & 13 & $31.7 \%$ \\
\hline Impaired nasal patency & 9 & $22 \%$ \\
\hline Suborbital oedema & 9 & $22 \%$ \\
\hline Postnasal drip & 7 & $17 \%$ \\
\hline Headache & 7 & $17 \%$ \\
\hline Earache & 5 & $12.2 \%$ \\
\hline No signs and symptoms & 5 & $12.2 \%$ \\
\hline Eyeball pain & 4 & $9.8 \%$ \\
\hline Epistaxis & 3 & $7.3 \%$ \\
\hline Numbness in cheek & 2 & $4.9 \%$ \\
\hline Conjunctivitis & 2 & $4.9 \%$ \\
\hline
\end{tabular}

No statistically significant differences were revealed in the frequency of occurrence of symptoms among women and men.

The Mann-Whitney test was used to check if some symptoms occurrence depended on the age of the patients. Pertinence level of $\mathrm{p}<0.05$ was applied and it did not indicate statistically significant differences.

Five patients had asymptomatic sinusitis and the pathology was revealed by chance in $\mathrm{x}$-rays taken for other reasons. All the patients underwent pantomography, and 15 patients had computed tomography which revealed partial or complete shadowing in the cavity of the maxillary sinus. Foreign body - some dental material pushed through the sinus vestibule during the endodontic treatment - was detected in the cavity of the sinus in 26 patients. Secondary sinus communication after teeth extraction was reported by 6 patients; 4 patients had been treated for a long time due to recurring upper airways infections; 2 patients developed maxillofacial traumas (in road traffic accidents); 3 remaining patients could not provide any explanation for the diagnosed disease. Table 4 shows data concerning the etiopathogenesis.

The Chi-quadrant test was used to check the occurrence of differences in the frequency of pathogenesis among the men and women. Pertinence level of $\mathrm{p}<0.05$ was applied and it did not indicate statistically significant differences. However, it should be highlighted that in this case the numbers did not comply with the rules of test application.

Table 4. Etiopathogenesis of the disease

\begin{tabular}{lc}
\hline Etiopathogenesis & No. of people $(\mathrm{n}=41)$ \\
\hline Endodontic treatment & 26 \\
\hline Fistula antro-oralis post- extractionem & 6 \\
\hline Recurrent respiratory tract infection & 4 \\
\hline Maxillofacial trauma & 2 \\
\hline No perceptible cause & 3
\end{tabular}

All of the 41 patients admitted to the Maxillofacial Surgery Clinic at the Medical University in Lublin during 2005 - 2014 due to non-invasive aspergillus maxillary sinusitis underwent the Caldwell-Luc surgery procedure. To date, none of the patients have reported the recurrence of the disease. 


\section{DISCUSSION}

Non-invasive maxilla sinus aspergillosisis is a rare condition, although some cases are not diagnosed due to atypical signs and symptoms, or lack of them [7,3]. Data in the presented study confirm the findings of other authors that the condition affects mostly elderly people with properly functioning immune system, and is more common among women $[3,4$, $5,6,7]$. New retrospective research conducted by Nomura et al. has shown that the number of men and women below 60 years of age was identical [16]. Thus, the hypothesis is proposed that the disease is more common in women because women live statistically longer than men [16]. In the case of the patients in the clinic in Lublin, women also outnumbered men in the younger age groups.

The invasive form of the disease is also possible when the immune system malfunctions. In extreme cases, the disease can be fulminant and may lead to death. In some rare cases the invasive form of the disease may affect patients without immune system malfunctions. Basic diagnosis ought to be expanded by CT and/or MRI. Research shows the development of aspergillosis in the cavity of the sinus may result from impaired ventilation [12], e.g. due to transmission of the infection from the oral cavity through the facialsinuses junction, or due to a foreign body which caused hyperaemia and oedema.

The role of zinc oxide (present in endodontic sealing) in fungal sinusitis is discussed. Some authors point out that zinc oxide evokes the growth of mycelium [10], whereas others have prove that it is not zinc oxide which causes fungal sinusitis, but problems with drainage and ventilation of the sinus [17]. Some authors confirm antimycotic activity of zinc oxide in in vitro research [12].

All the authors are unanimous about the visible correlation between occurrence of maxilla sinuses aspergillosis and endodontic treatment of maxillary premolar and molar teeth $[7,11,18]$. This correlation is also noted in the above study.

Surgical treatment of maxilla sinuses aspergillosis is chosen in the presented study. Research shows that in the case of non-invasive form of the disease there is no need to introduce antimycotic pharmacological treatment after removing a pathological mass from the cavity of the sinus [7]. Nor is there any need for complete mucosal resection, even if it demonstrates hyperplastic changes [19]. If the disease is invasive, pharmacological treatment is obligatory. Amfotericin B, which can be substituted by Vorkinazole due to its neurotoxic activity, is used to treat severe forms of the disease [20]. In the case of non-invasive forms of the disease, apart from antimycotic treatment, immune deficiency should be compensated and the primary disease that caused it should be treated [21].

Surgical treatment of maxillary sinusitis include the classic Caldwell-Luc procedure and endoscopic methods (FESS - Functional Endoscopic Sinus Surgery). Modern surgery aims at minimalizing the invasiveness of the procedure; consequently, the Caldwell-Luc procedure loses its importance in endoscopic procedures. Nevertheless, there are still some indications for the classical surgical procedure. In 2006, Stankiewicz and Misiołek carried out a review of the medical literature to determine indications for the Caldwell-Luc procedure which include maxillary sinus mycoses with aspergillosis, antrochoanal polyp, mucocele, as well as chronic sinusitis persisting despite intensive noninvasive and endoscopic treatment [22].

The advantage of the classic surgical procedure is lack of relapses recorded $[1,6]$. Postoperative complications include cheek oedema, bleeding, numbness in the cheek and pain [23]. Extreme cases may lead to the patient's death [7]. Relapses have not been reported in the patients treated at the Maxillofacial Surgery Clinic at Medical University in Lublin, which is in accordance with the results of other researchers $[1,6]$.

\section{CONCLUSIONS}

1) Risk factors for the disease emergence are maxillary teeth endodontic treatment and fistula antro-oralis.

2) Aspergillosis of the maxillary sinus should be taken into account in every case of chronic sinusitis resistant to standard treatment.

3) The disease is non-invasive in patients without immune deficiency, and the treatment involves the Caldwell-Luc surgical removal of mycelium mass from the cavity of the sinus.

\section{REFERENCES}

1. Costa F, Polini F, Zerman N, Robiony M, Toro C, Politi M. Surgical treatment of aspergillus mycetomas of the maxillary sinus: review of the literature. Oral Surg Oral Med Oral Pathol Oral Radiol andEndod. 2007; 103: 23-29.

2. Rudzki E. Alergeny. Odcinek 71 Aspergillus (narażenie niezawodowe). Med. Prakt. 2001; 11: 186-187 (in Polish).

3. Klempous J, Pośpiech L, Rak J. Fungal rhinosinusitis. Medical mycology. 2000; 7: 99-105.

4. Krzeski A, Donald C, Lanza C. Grzybica zatok przynosowych. In: Krzeski A, Janczewski G. Choroby nosa i zatok przynosowych. Warszawa, Sanmedia, 1997.p 229-237 (in Polish).

5. deShazo RD, O’Brien M, Chapin K, Soto-Aguilar M, Swain R, Lyons $\mathrm{M}$ et al. Criteria for the diagnosis of sinus mycetoma. J Allergy Clin Immunol Pract. 1997; 99, 4: 475-485.

6. Ferreiro JA, Carlson BA, Cody DT. Paranasal sinus fungus balls. Head Neck. 1997; 19, 6: 481-486.

7. Eloy Ph, Grenier J, Pirlet A, Poirrier AL, Stephens JS, Rombaux Ph. Sphenoid sinus fungall ball: a retrospective study over a 10-year period. Rhinology. 2013; 51-2: 181-188.

8. Krennmair G, Lenglinger F, Muller-Schelken H. Computed tomography in the diagnosis of sinus aspergillosis. J Craniomaxillofac Surg. 1994; 22, 2: 120-125.

9. Martins WD, Ribeiro Rosa EA. Aspergillosis of the maxillary sinus: review and case report. Scand J Infect Dis. 2004; 36: 758-761.

10. Beck-Mannagetta J, Necek D. Radiologic findings in aspergillosis of the maxillary sinus. Oral Surg Oral Med Oral Pathol Oral Radiol and Endod. 1986; 62: 345-349.

11. Burnham R, Bridle C. Aspergillosis of the maxillary sinus secondary to a foreign body (amalgam) in the maxillary antrum. J Oral Maxillofac Surg Med Pathol. 2009;47:313-315.

12. Odell E, Pertl C. Zinc as growth factor for Aspergillus sp. and the antifungal effects of root canal sealants. Oral Surg Oral Med Oral Pathol Oral Radiol and Endod. 1995; 79, 1: 82-87.

13. Giardino L, Pontieri F, Savoldi E, Tallarigo F. Aspergillus mycetoma of the maxillary sinus secondary to overfilling of a root canal. J Endod. 2006; 32, 7: 692-694.

14. Chobillon MAJ, Jankowski R. What are the advantages of the endoscopic canine fossa approach in treating maxillary sinus aspergillomas? Rhinology, 2004; 42, 4: 230-235.

15.Lai JC, Lee HS, Chen MK, Tsai YL. Patient satisfaction and treatment outcome of fungus ball rhinosinusitis treated by functional endoscopic sinus surgery. Eur Arch Otorhinolaryngol.2011; 268, 2: 227-230.

16. Nomura K, Asaka D, Nakayama T, Okushi T, Matsuwaki Y, Yoshimura T, et al. Sinus Fungus Ball in the Japanese Population: Clinical and Imaging 
Characteristics of 104 Cases. Int J Otolaryngol. 2013; Article ID 731640 4 pages, http://dx.doi.org/10.1155/2013/731640 (access: 2014.03.25)

17. Dufour X, Kauffmann-Lacroix C, Ferrie JC, Goujon JM, Rodier MH, Karkas A et al. Paranasal sinus fungus ball and surgery: a review of 175 cases. Rhinology. 2005; 1: 34-39.

18. Park GY, Kim HY, Min JY, Dhong HJ, Chung SK. Endodontic treatment a significant risk factor for the development of maxillary fungal ball. Clin Exp Otorhinolaryngol. 2010; 3: 136-140.

19. Nicolai P, Lombardi D, Tomenzoli D, Villaret AB, Piccioni M, Mensi M et al. Fungus ball of the paranasal sinuses: experience in 160 patients treated with endoscopic surgery. Laryngoscope. 2009; 119: 2275-2279.
20. Nakaya K, Oshima T, Kudo T. New treatment for invasive fungal sinusitis: three cases of chronic invasive fungal sinusitis treated with surgery and voriconazole. Auris Nasus Larynx. 2010; 37, 2: 244-249.

21. Tomczak H. Fungal infection in laryngology - problem of diagnosis and treatment. Advances in head and neck surgery. 2008; 2: 51-57.

22. Stankiewicz C, Misiołek M. Miejsce operacji Caldwella-Luca we współczesnej rynologii [Place of Caldwell-Luc surgery in contemporary rhinology]. Magazyn Otolaryngologiczny. 2006; 5, 4: 107-110 (in Polish).

23. Minutha R, Sriram N. A study of Caldwell-Luc approach in various etiologies. Journal of Evolution of Medical and Dental Sciences. 2013; 2(36): 7015-7023. 